\title{
Tensiones culturales en adolescentes migrantes residentes en Chile
}

\author{
Nicolás Vera-Álvarez, $\mathbf{M g} .^{a}$ \\ Universidad de La Frontera, Chile \\ Sandra Riquelme-Sandoval, Ph.D. ${ }^{b}$ \\ Universidad de La Frontera, Chile
}

nicolas.vera@ufrontera.cl

\section{Resumen (analítico)}

Las migraciones contemporáneas han desafiado significativamente el desarrollo de las parentalidades en el núcleo de la familia transnacional. Resulta de interés acercarnos a las tensiones culturales que afrontan adolescentes migrantes desde sus significados, deconstruyendo lógicas adultocéntricas que los han invisibilizado como sujetos protagónicos. Este estudio contó con la participación de adolescentes migrantes provenientes de Colombia, Haití y Venezuela, cuyas familias residen en Chile. A partir de entrevistas en profundidad, se realizó un análisis desde un enfoque constructivista de los principales resultados respecto a tensiones culturales vivenciadas por los y las adolescentes en el ámbito individual y familiar, destacando en este último los estilos educativos y la apertura cultural, desplegándose distintos mecanismos de resolución o afrontamiento, tales como la integración, resistencia y exclusión.

\section{Palabras clave}

Inmigración; relaciones culturales; adolescencia; familia.

\section{Thesauro}

Tesauro de Ciencias Sociales de la Unesco.

\section{Para citar este artículo}

Vera-Álvarez, N, \& Riquelme-Sandoval, S. (2022). Tensiones culturales en adolescentes migrantes residentes en Chile. Revista Latinoamericana de Ciencias Sociales, Niñez y Juventud, 20(1), 1-21. https://dx.doi.org/10.11600/rlcsnj.20.1.5079

\section{Historial}

Recibido: 09.09.2021

Aceptado: 09.11.2021

Publicado: 17.12.2021

\section{Información artículo}

El artículo presenta resultados de la investigación Trayectorias migratorias en la voz de los y las adolescentes en procesos de construcción identitaria: significados y experiencias desde la región de la Araucanía. Estudio patrocinado por el proyecto "Converging Horizons: Production, Mediation, Reception and Effects of Cultural Representations of Marginality" (SOC180045), financiado por la Agencia Nacional de Investigación y Desarrollo de Chile. El proyecto se realizó entre el 9 de marzo de 2020 y el 31 de marzo 2021. Área: ciencias sociales. Subárea: comunicación. 


\section{Cultural tensions in migrant adolescents living in Chile}

\section{Abstract (analytical)}

Contemporary migration patterns have significantly challenged the role of parenting in transnational families. Faced with this scenario, this study enquires about the cultural tensions faced by migrant adolescents through their meanings, deconstructing adult-centered logics that have made them invisible as subjects. This study included the participation of migrant adolescents from Colombia, Haití and Venezuela whose families are living in Chile. Following the in-depth interviews, an analysis was carried out using a constructivist approach. The main results highlighted the cultural tensions experienced by adolescents in both individual and family spheres of life. Within their families, they highlighted cultural differences in terms of educational styles and cultural openness. The adolescents deploy different resolution and/or coping mechanisms, such as integration, resistance and exclusion. Keywords Immigration; cultural relations; adolescence; family.

\section{Tensões culturais em adolescentes migrantes residentes no Chile}

\section{Resumo (analítico)}

As migrações contemporâneas têm desafiado significativamente o desenvolvimento das relações parentais no seio da família transnacional. Diante desse cenário, interessa abordar as tensões culturais enfrentadas pelos adolescentes migrantes a partir de seus significados, desconstruindo lógicas adultocêntricas que os têm invisibilizado como sujeitos protagonistas. Este estudo contou com a participação de adolescentes migrantes da Colômbia, Haiti e Venezuela, cujas famílias residem no Chile. Partindo das entrevistas em profundidade, procedeu-se uma análise desde um enfoque construtivista dos principais resultados relativos às tensões culturais vivenciadas pelas e pelos adolescentes no âmbito individual e familiar, destaca-se neste último, os estilos educacionais e a abertura cultural, implantando distintos mecanismos de resolução e/ou enfrentamento, tais como a integração, resistência e exclusão.

Palavras-chave

Imigração; relações culturais; adolescência; família.

Información autores

[a] Trabajador Social, Mediador Familiar y Comunitario. Magíster en Estudios y Desarrollo de la Familia, Universidad de La Frontera. Coordinador Académico del Programa de posgrado Estrategias de Intervención con Niñas, Niños y Adolescentes en Contextos Socioculturales Diversos. iD 0000-0002-3148-8307. H5: 0. Correo electrónico: nicolas.vera@ufrontera.cl

[b] Trabajadora Social. Magíster en Ciencias Sociales Aplicadas, Universidad de La Frontera. Doctora en Procesos Sociales y Políticos en América Latina, Universidad Arcis, Chile. Directora del Programa de posgrado Estrategias de Intervención con Niñas, Niños y Adolescentes en Contextos Socioculturales Diversos. (iD) 0000-0002-2442-0339. H5: 3. Correo electrónico: sandra.riquelme@ufrontera.cl 


\section{Introducción}

ـ a sociedad actual como escenario mundial de transformaciones sociales, cultulidades y sistemas de cuidado. Muchas de estas se distancian significativamente de lógicas tradicionalistas de entender a la familia, como también sus prácticas y relaciones. En este sentido, en estas nuevas configuraciones familiares persiste una invisibilización o no reconocimiento de familias distanciadas de visiones morales o culturalmente hegemónicas.

En este contexto, podemos reconocer históricamente la existencia de familias en procesos de movilidad humana. Sin embargo, no es sino hasta fines del siglo XX cuando, a partir del concepto de transnacionalismo y sus discusiones e implicancias, comienza a posicionarse la familia transnacional como una categoría de análisis. Diversos investigadores han planteado definiciones de esta noción, cuya concepción más tradicional se remite a la separación física de manera parcial o total y la creación de vínculos por parte de sus miembros, de modo que se perciba el bienestar en la dimensión colectiva a pesar de la distancia (Gonzálvez, 2016). En esta misma línea, autores relevan el sentido de unidad que perciben los miembros, reforzada por el mantenimiento fluido de la comunicación y el intercambio (Fernández-Hawrylak \& Heras, 2019; Ramírez, 2020).

En efecto, conceptualmente la familia transnacional no ha estado exenta de cuestionamientos, surgiendo como principal crítica la centralidad que se le otorga a la dicotomía distancia/proximidad. Sin embargo, existen enfoques que contemplan nuevos elementos respecto a la dinámica familiar, destacando la estructuración de un hogar en el escenario familiar virtual y la superación de los enfoques biologicistas, centrado en las relaciones de consanguineidad:

Si por transnacional se quiere considerar innovadoramente a las familias, debe observarse esa tensión entre lo biológico y la elección, yendo más allá de la dicotomía distancia-proximidad geográfica, porque desde este enfoque, será posible investigar otros escenarios familiares que aparecen hoy día invisibilizados producto de la esencialización que existen 
entre mujer y maternidad, paternidad-proveedor, también desde la relación familiar transnacional. (Lemus, 2020, p. 69)

En síntesis, el sentido de familia transnacional en la actualidad está construido desde los intercambios generados, los modos de interacción cotidiana que hoy permiten las redes sociales y los medios de comunicación (Ramírez, 2020), además del intercambio que se da en el plano económico donde —en muchas ocasiones - se mantiene un rol de proveedor por parte del migrante hacia su familia de origen por medio del envío de remesas y bienes; como también, de aquellas remesas sociales expresadas en el apoyo emocional y el soporte afectivo que transita por parte de la familia hacia los distintos lugares de residencia. Un compartir de experiencias, valores, sentimientos y todo aquel componente simbólico propio de la interacción familiar.

Sin perjuicio de lo anterior, dichas conceptualizaciones de familia transnacional dejan entrever estructuras adultocéntricas (Duarte, 2015) que invisibilizan la capacidad de agencia de niños, niñas y adolescentes y las relaciones de poder que se establecen con sus cuidadores; es allí donde no debemos perder de vista su participación en tanto sujetos protagónicos del proceso, habitualmente limitado a su consideración en torno a aspectos domésticos o justificados desde el cómo inciden en el mundo adulto, en su defecto, visibilizados como fuente de preocupación y ansiedad de sus adultos significativos (Zúñiga, 2017). En tal sentido, cobra relevancia poder considerar, no tan solo una parte del proceso migratorio, sino más bien comprender holísticamente las trayectorias vivenciadas y construidas, tanto por la familia en su conjunto como también a partir de las individualidades y múltiples perspectivas, interpretaciones y significados de sus actores; principalmente de aquellos invisibilizados por el mundo adulto, tales como niñas, niños y adolescentes. Se destaca la necesidad imperiosa de incorporar un foco en estos sujetos, puesto que,

la incorporación del enfoque centrado en la infancia en la perspectiva transnacional puede proporcionar una mirada más adecuada para investigar la realidad de los NNA migrantes dentro de la familia transnacional, lo que permitirá mejorar la comprensión de la temporalidad, las emociones, el género y los lazos transnacionales en tales contextos. (Arriagada, 2019, p. 113)

Por tanto, destacamos la función socializadora que cumple la familia como un aspecto crucial en la construcción y conformación de una identidad grupal de carácter colectivo que en su seno, y a partir de prácticas cotidianas, se reproduce y transmite (HenaoAgudelo et al., 2016), por medio de la enseñanza de pautas comportamentales y valores 
propios de la cultura, los cuales se van perpetuando o resignificando a través de las generaciones (Comas \& Pujadas, 1991, como es citado en Bravo et al., 2021). En tal sentido, los desafíos de la parentalidad migrante se evidencian en la interacción con el contexto de destino, específicamente con actores e instituciones que significan e interpretan prácticas parentales influenciadas por la cultura hegemónica. La vinculación entre parentalidad migrante y vulnerabilidad es algo que, no solo se acentúa en los imaginarios colectivos, sino que responde a paradigmas institucionales que invisibilizan las particularidades culturales y trayectorias, reproduciendo y perpetuando dicha idea, ya que,

en la práctica se han pasado por alto las precauciones de contextualización de las trayectorias de las familias migrantes que, de otra forma, pudieran evitar sesgos estigmatizadores, generalizaciones y modelización del concepto de marentalidad/parentalidad. (PavezSoto et al., 2020, p. 17)

Las trayectorias migratorias y el proceso de construcción identitaria están intrínsecamente relacionados, en tanto dichas trayectorias, no solo se asocian a un mero recorrido o tránsito por parte de un sujeto (como tampoco se comprenden exclusivamente en términos territoriales), sino que adquieren relevancia en cuanto la posición/estatus del sujeto migrante cambia, al igual que su pertenencia a los distintos contextos; vale decir, su condición se ve modificada según la fase o etapa de la trayectoria migratoria en la que se encuentre. Esto, a su vez, conlleva un proceso de resignificación identitaria, puesto que dicha posición tiene una implicancia individual para el sujeto, como también la exposición a la mirada de su entorno; este, a su vez, es un marco de referencia para ser considerado desde la no pertenencia o desde la otredad o alteridad, según sea el grupo nacional de origen del sujeto adolescente migrante.

El momento de la inmigración supone una serie de desafíos desde el punto de vista cultural, los cuales pueden verse incrementados de acuerdo a las distancias culturales existentes entre el país de origen y de destino, así como también a la permeabilidad o apertura cultural de ambas partes. Para comprender de mejor manera el concepto y adentrarnos a las tensiones culturales abordadas en este artículo y que afrontan adolescentes migrantes, entendemos por cultura al conjunto de conocimientos, creencias, costumbres y la comunicación, entre otros elementos, que se adquieren mediante la experiencia vital de la interacción social, mediada por agentes socializadores primarios como la familia. (Romero et al., 2021). 
A partir de la interacción de inmigrantes en el nuevo contexto de destino es posible que existan diferencias más o menos significativas dentro de los elementos que conforman la identidad cultural; ante esto, podemos observar que existen culturas en las cuales encontramos elementos que resultan más distantes o, en ocasiones, ser considerados como contrarios a la propia cultura. La tensión cultural es algo que puede considerarse como un desafío a sortear en el proceso de inmigración. Para esto, y en el marco de los estudios sobre migraciones, se ha planteado una clasificación de posicionamientos de los inmigrantes hacia la cultura del país receptor, dentro de las cuales encontramos la asimilación, la aculturación, la exclusión y la marginación (Berry, 1997, como es citado en Martín, 2017). Dichas investigaciones se han aventurado a explorar la relación entre aculturación, adaptación, bienestar social y psicológico en la población migrante general (Ramírez, 2021) como también estudios en adolescentes (Pareja, 2019; Sánchez-Castelló et al., 2020).

Estos posicionamientos también han sido ampliamente estudiados en el contexto europeo sobre las migraciones de población latina, africana y de medio oriente, a partir del modelo ampliado de aculturación relativa. Este contrasta las opciones de aculturación desde la perspectiva de la población migrante y la población local o autóctona, estableciendo - a partir de la proximidad o distancia entre el plano ideal y el real-qué tipo de estrategia de aculturación estaría mayormente presente. El modelo tiene como premisa que el proceso adaptativo es complejo y relativo, pudiendo cada persona desarrollar más de una estrategia dependiendo del ámbito sobre el cual se está interactuando (VelandiaCoustol et al., 2018)

De esta forma, las tensiones culturales o, como señalan Aparicio y Tornos (2009), frustraciones y conflictos culturales, son aspectos que se asemejan a heridas de segundo nivel; esto dado que no siempre son evidentemente visibles, debido a su mayor profundidad, ya que dan cuenta de un modo de interacción de los y las individuos, en tanto impacta sobre las funciones cognitivas, identitaria y sociohistóricas de la cultura que le otorga seguridad al sujeto. En otras palabras, las posibles consecuencias de dicha tensión cultural pudieran asociarse a:

Perder la posibilidad de comprender espontánea e inmediatamente las situaciones que atraviesan, al de perder su lugar acostumbrado en el sistema de las identidades que articulaba la interacción en sus ambientes de origen, y al de perder las referencias contextuales que les permitían sentirse autores responsables de su propia vida. (Aparicio \& Tornos, 2009, p. 149) 
Respecto a lo anterior, el modo de resolución de dichas tensiones culturales o estrategias de afrontamiento incidirán directamente en el grado de inclusión de adolescentes migrantes en la sociedad de destino. Sobre esta línea, estudios recientes han apuntado a mirar cómo una cultura adaptativa (entendida como el acomodar aspectos relativos al uso del lenguaje y acoplar los valores familiares de origen al contexto del país receptor) tendrían una incidencia en la integración de adolescentes migrantes en el medio (Wheeler et al., 2020).

De esta forma, posicionándonos desde la experiencia de los actores, surgen como interrogantes: ¿cuáles son las tensiones culturales vivenciadas por adolescentes migrantes en Chile en el ámbito individual y familiar? Y frente a estas tensiones culturales, ¿cuáles son los mecanismos de resolución implementados como estrategias de afrontamiento? Los modos de resolución de las tensiones culturales identificadas, ¿son conducentes a la inclusión de adolescentes migrantes? En este sentido, en este documento nos hemos trazado como objetivo el analizar las tensiones culturales vivenciadas por adolescentes migrantes y los mecanismos de resolución implementados a nivel individual y familiar.

\section{Método}

\section{Fundamentación epistemológica}

La naturaleza de este estudio es cualitativa, el cual se posiciona desde un enfoque constructivista, que pretende comprender en profundidad y de manera integral el fenómeno en estudio, como proceso de construcción intersubjetiva que implica abordar los sentidos e interpretaciones desde los significados otorgados por los/as mismos/as sujetos. De esta forma, se releva la subjetividad de las trayectorias que, exclusivamente, las adolescencias migrantes pueden identificar y describir desde su propia experiencia constitutiva de sujetos migrantes. El diseño utilizado en esta investigación es el estudio de caso múltiple por país de origen (Colombia, Haití y Venezuela), fundamentados en la relevancia de conocer los elementos de la experiencia personal diferenciada, en tanto adolescentes pertenecientes a grupos migrantes de flujos migratorios emergentes en Chile.

\section{Técnica de recolección de datos}

En concordancia al enfoque cualitativo, la técnica de recolección de datos utilizada fue la entrevista en profundidad, orientada hacia la comprensión de las perspectivas, 
experiencias y significancias expresadas por adolescentes migrantes, por medio de una guía de entrevista por campo semántico en exploración (Campoy \& Gómez, 2009, como son citados en Sánchez et al., 2021).

\section{Sujetos participantes}

Dada la metodología de investigación, el muestreo utilizado fue de sujeto tipo, participando un total de nueve adolescentes migrantes. Como criterios de inclusión se definieron los siguientes: adolescentes entre los 14 y 18 años de edad, nacidos en Colombia, Venezuela o Haití, que desearan participar voluntariamente del estudio (asentimiento) y que contaran con la autorización de sus padres o tutores legales para poder participar de las actividades asociadas a la investigación (consentimiento). Se considera como criterio de inclusión la nacionalidad, debido a lo que se denomina «migración emergente» y flujos significativos, como es el caso de los países señalados precedentemente. Por último, también se consideraron como criterios, el que los y las adolescentes residan junto a sus familias a lo menos un año en Chile y que cuenten con la capacidad de comunicarse verbalmente en español.

\section{Procedimientos}

En relación al trabajo de campo, se gestionaron los contactos con los y las participantes a través de la difusión y coordinación con directores y directoras de organizaciones de la sociedad civil en la región de la Araucanía (Chile), específicamente, fundaciones que brindan apoyo mediante intervenciones psicosociales con población migrante, tales como: Fundación Social Remanente, Fundación Madre Josefa, Fundación Gzo y la Agrupación Colombianos por Siempre (Riquelme-Sandoval et al., 2019). Una vez identificados los posibles adolescentes y familias interesadas en participar voluntariamente, se establecieron los contactos telefónicos para acordar día y hora de aplicación, además del envío de consentimiento informado y asentamiento informado, invitándoles a concretar el compromiso por medio de la firma de padres/madres/adulto tutor legal responsable y adolescentes participantes. Las entrevistas fueron realizadas en la ciudad de Temuco, entre el 15 de septiembre y el 25 de octubre del 2020, cuya duración promediaba los 45 minutos.

Cabe consignar los resguardos éticos adoptados, ya sea en la elaboración de guías de entrevista y procedimientos empleados, contando con las debidas certificaciones y autorizaciones del Comité Ético Científico de la Universidad de La Frontera, acreditado en el marco de la normativa nacional e internacional vigente en la materia. 


\begin{abstract}
Análisis
El corpus de la investigación estuvo constituido por las unidades discursivas obtenidas a través de entrevistas en profundidad. Se empleó como técnica el análisis de discurso y como mecanismo informático auxiliar el software ATLAS.ti (v. 8.4.4). Como método para la interpretación de los textos se empleó una estrategia inductiva, la cual consistió en la identificación y comparación de códigos a partir de las subunidades discursivas más relevantes de los documentos primarios o transcripciones de las entrevistas en profundidad. En un nivel de abstracción mayor, se utilizó como técnica la redacción de memos, los cuales permitieron la incorporación de notas y reflexiones teóricas emergentes durante el proceso de codificación. El análisis de realizó en cinco etapas (Strauss \& Corbin, 2002): transcripción de las entrevistas, codificación abierta, codificación axial (que permitió identificar las familias de códigos y las relaciones explicativas entre los códigos de cada categoría), codificación selectiva (en la cual los investigadores enjuiciaron la centralidad de las categorías para responder la pregunta de investigación) y, finalmente, se dispuso la información en redes que permitieron graficar las relaciones, expresando condiciones, contextos y dimensiones de los discursos.
\end{abstract}

\title{
Resultados
}

A partir del trabajo de análisis y codificación de la información recogida, se identifica como unidad categorial a las tensiones culturales (tabla 1). Su presentación será desarrollada por objetivos vislumbrando resultados y respectiva discusión. De esta manera, se describirán las tensiones culturales vivenciadas por adolescentes migrantes participantes en este estudio diferenciados por país de origen.

\section{Tabla 1}

\section{Unidad categorial: tensiones culturales}

\begin{tabular}{lcc}
\hline \multicolumn{1}{c}{ Individual } & Familiar & Mecanismos de resolución \\
\hline Manejo del idioma & Apertura cultural & Integración \\
Tipo de interacción con pares & Estilos educativos familiares & Resistencia \\
Identidad social & & Exclusión \\
\hline
\end{tabular}

Como se observa en la tabla 1, se pueden identificar tres categorías emergentes de los discursos. En primer lugar, tensiones culturales producidas en el nivel individual, 
desde la propia experiencia de los y las adolescentes en los contextos de interacción más próximos. Como segunda categoría, las tensiones producidas a nivel familiar, lo cual involucra al sistema en su conjunto y a las percepciones emanadas desde este. Por último, la categoría mecanismos de resolución aborda los modos o estrategias de resolución de los y las participantes y sus respectivas familias frente a las situaciones de tensión.

En primer lugar, podemos ver que, en la dimensión individual emerge como subcategoría el manejo del idioma, situación que alude principalmente a adolescentes haitianos, quienes reconocen al creole como lengua materna y cuyo manejo idiomático podría extenderse al francés e inglés básico como conocimiento adquirido por medio de la educación formal en su país de origen. Lo anterior se transforma en un obstaculizador para la interacción de adolescentes en el nuevo contexto, al momento de interactuar con adultos en lugares públicos, como también en la interacción con sus pares en el contexto social o escolar. Ello se manifiesta en sus relatos:

No hablaba nada, nada de español y cómo se dice; no, sí sabía cómo se decía ¿cómo estás?, porque en mi escuela como que aprende inglés y español, pero sabía como poquito de español, como hola, ¿cómo estás?, si, no y todo eso, pero no sabía nada... [Posteriormente relata la experiencia de ingreso a un establecimiento educacional, ante lo cual comenta] Mi mamá va a dejarme a la escuela como, qué voy a hacer ahí no voy a entender nada allí, cómo voy a decir profesor, cómo voy a decir alli y cómo voy a decir que necesito algo para mí. (Sujeto 7 , femenino, 15 años, Haití)

Eh, difícil igual, porque ellos me saludaban y yo no sabía cómo saludarlos [Entrevistador le consulta el motivo] - Porque no sabía español [Entrevistador confirma manejo del idioma, consultando ¿Hablabas poquito o hablabas nada de español?] —Nada, absolutamente nada [Entrevistador consulta: ¿cómo lo hacías para comunicarte?, ¿quién te ayudaba?] —Eh, mi papá porque él sabía y me enseñó. Ahí aprendí. (Sujeto 9, masculino, 16 años, Haití)

Como se observa, hay dos puntos interesantes de análisis: por una parte, podemos ver que el manejo idiomático puede ser considerado como tensión o conflicto cultural, en cuanto no tan solo existen dificultades evidentes para poder comunicarse con otros e interactuar, sino que también ello gatilla frustraciones (Aparicio \& Tornos, 2009) y emociones de temor o estrés frente a la inevitable interacción en contextos recurrentes y significativos, como puede ser la escuela. En este sentido, el conflicto reviste mayor profundidad en un plano psicosocial, pero también en los componentes cognitivos de la cultura e identitarios, ya que de acuerdo a los resultados de otras investigaciones (Pavez- 
Soto et al., 2019; Poblete \& Galaz, 2017) la barrera idiomática opera como un factor transversal que impacta en el acceso al sistema educativo y a las relaciones entre pares, puesto que no se cuenta con políticas públicas o una oferta programática que aborde la inmersión lingüística como una prioridad.

Frente a esta barrera resulta importante señalar los mecanismos a través de los cuales los y las adolescentes resuelven esta brecha y tensión; solo a modo de ejemplo, podemos observar que al menos una posibilidad de aprendizaje se encuentra mediada en torno a la familia, en específico la persona que posee algún tipo de conocimiento previo mayormente avanzado, generalmente representado por la figura paterna, para el caso de la población haitiana.

Dentro de esta subcategoría, cabe relevar que el manejo idiomático, no solo resulta en una tensión cultural para quienes su lengua materna no es el español, sino también en cuanto las variantes lingüísticas en distintos planos, pero también a partir de los modismos verbales propios de cada país.

Aquí no entenderían de pronto una palabra que yo les dijera...; un chileno por ahí también hay palabras que no se entiende porque dicen palabras que yo aquí no voy a entender. Por eso a veces cuando se están riendo, dicen un chiste o algo y no lo entiendo y me rio para no quedar mal. (Sujeto 3, masculino, 16 años, Colombia)

Se me dificulta y a eso sumarle que ustedes tienen una jerga diferente a la mía, la cual yo desconozco demasiado. Entonces a veces me dicen palabras que no entiendo y es como súper difícil preguntarles a cada momento qué significa esto, qué significa lo otro. (Sujeto 6, masculino, 16 años, Venezuela)

Como se muestra en los relatos, los y las adolescentes reconocen una dificultad importante para la integración o inclusión en términos de la falta de comprensión de algunas situaciones producto del manejo idiomático o de variantes lingüísticas presentes en la interacción cotidiana, especialmente con sus pares, lo que resulta de gran relevancia en el caso de adolescentes en proceso de construcción identitaria.

Respecto a lo señalado anteriormente, la segunda subcategoría se relaciona con el tipo de interacción con pares, en donde observamos el bullying en el plano escolar que marca la experiencia de interacción con pares del país de destino. Cabe destacar que, de acuerdo a diversos estudios, existen antecedentes que relevan como parte de los motivos de violencia y acoso escolar a los estereotipos y estigmas asociados a identidades nacionales, como también una concentración de dichas conductas dirigidas a niños, niñas y 
adolescentes afrodescendientes. De acuerdo a lo señalado por Poblete y Galaz (2017), las actitudes de aprensión o rechazo hacia niños, niñas y adolescentes en el contexto escolar, tienen una implicancia y afectación en el rendimiento educativo, como también en la generación de niveles de angustia que, por lo general, no se logran abordar en los contextos escolares. Así, el bullying se constituye en un tipo de interacción violenta con pares que funciona como mecanismo de racialización en la comunidad educativa (Masferrer, 2016; Pavez-Soto et al., 2018). Por otra parte, también se observan tensiones en la interacción con pares connacionales, quienes ejercen presión para la consolidación de una identidad cultural monocultural, en donde los y las adolescentes no incorporen elementos del país de origen, manifestándoles que «no se chilenicen». Esto es relevante en tanto se visualiza la reproducción y transmisión cultural por pares desde el espacio transnacional.

La tercera subcategoría, referida a la identidad social construida por los y las adolescentes en torno al proceso migratorio, produce tensiones en cuanto existe una distancia entre cómo la o el adolescente se visualiza y la identidad atribuida por la comunidad de destino, asociada a cargas estereotipadas según grupo nacional y estigmatizadoras respecto a aspectos raciales. A continuación, se exponen algunos relatos que refuerzan lo señalado:

Es como un estereotipo, porque si el prototipo de la venezolana es tener figura, tener pechos, todo eso y normal; sin embargo, no todas son así o no todas somos así, entonces como, ay, de dónde eres tú - ay, soy de Venezuela, y se te quedan viendo, así como, no pareces. (Sujeto 2, femenina, 15 años, Venezuela)

Muchas veces me ha tocado escuchar como decir que los colombianos somos..., las mujeres somos putas. (Sujeto 5, femenino, 14 años, Colombia)

Podemos observar que los y las adolescentes reconocen en sus relatos la exposición a un marco de referencia social asociado a prejuicios que les posicionan frente a comparaciones y exigencias. Respecto al contenido de estos estereotipos, tal como señala Viveros (2009, como es citado en Tijoux \& Palominos, 2015), en general, hay una exploración incipiente de estudios asociados a vincular la sexualización y racialización en Latinoamérica, principalmente debido a la hegemonía de un discurso racial que asocia al erotismo, lo que está fuera de la blanquitud. Sin embargo, podemos sostener que el estereotipo como idea preconcebida y estructurada de conocimiento presente en el imaginario colectivo, sin duda, es un punto de comparación constante para los grupos asociados, en este caso, niños, niñas y adolescentes cuya identidad puede tomar elementos del plano social en su 
construcción. De esta forma, preocupa que dicha construcción de una identidad social se desarrolle bajo la sombra del estereotipo y la discriminación o violencia, como es el caso de las situaciones de bullying mencionadas anteriormente, puesto que, tal como señala Ibáñez (2020), «se entiende que toda construcción identitaria es una construcción social al ser necesariamente relacional e intersubjetiva» (p. 27o).

Como segunda categoría, aparece el plano familiar y las tensiones culturales que en este se manifiestan. Su primera subcategoría es la apertura cultural, referida a los valores y costumbres adquiridos desde la cultura de origen y el contraste originado a partir del contacto con la sociedad de destino. Ante esto, podemos advertir situaciones que podríamos catalogar como de choque cultural:

Sobre el consumo de la marihuana, ha sido algo que no veía mal desde Venezuela, pero que acá lo aprendí a ver técnicamente casi como de la vida cotidiana por mis compañeros que en sí la consumen. Entonces como que es un tema tabú en Venezuela y que acá sea tan abierto; hay tiendas sobre eso y ese tipo de cosa. Esto se ve esto acá, esto es normal acá. ¿Sabes?, he aprendido mucho de eso y me ha tocado en parte a mi enseñarle a mis papás a tener mente más abierta con respecto a esos temas... [Entrevistador consulta si hay otro tema que haya originado algún tipo de tensión respecto de su apertura cultural] -El demuestro de afecto en público también es otro tema que acá se ve muchísimo tanto de parejas heterosexuales como homosexuales, y si con parejas heterosexuales se les hacía incómodo a mis papás ver ese tipo de cosas, no creo que te imagines como será con parejas homosexuales que los vean ellos. Por ese lado sí es impresionante; me impresiono, no por el hecho de que exista, sino por el hecho de que no lo veía muy seguido. (Sujeto 6, masculino, 16 años, Venezuela)

Fui con mi uniforme nosotros con falda para usar y la señora me dijo que la falda llegaba aquí [indica la rodilla] y mi mamá dijo que estaba muy corta, como me van a mirar los hombres, todo eso [risas]; me van a mirar los hombres [risas]. Y las madres haitianas son muy celosas también porque podemos pololear a los dieciocho años, como dieciocho años más o menos; no todas las madres aceptan eso, como veinte, veinticinco las personas podían pololear. Si lo haces a los catorce te matan si saben que estás pololeando; te matan, te matan [risas]. Y eso le dije, que la falda tiene que estar aquí señora [a la rodilla] no acá [bajo la rodilla] y mi mamá aceptó eso. (Sujeto 7 , femenino, 15 años, Haití)

Podemos ver que, en general, las situaciones señaladas muestran resistencias culturales, principalmente por parte de adultos quienes tienen mayormente incorporados aspectos valóricos y morales del país de origen, que entran en tensión con una realidad significada como más conservadora respecto de la sociedad chilena. En este sentido, el 
rol de los y las adolescentes resulta ser el de mediador/a para la comprensión de la realidad por parte de sus cuidadores, cristalizando sentidos a efecto bisagra cultural.

Sin duda, esta realidad es relevante al entender cómo las parentalidades se co-construyen y regulan a partir de la transmisión que los y las adolescentes hacen a sus cuidadores de lo que acontece en el espacio social. Ello también supone que son las nuevas generaciones quienes, por el tipo de interacción que establecen con nacionales del país de destino, tienen la capacidad de significar con mayor claridad los códigos culturales que se expresan en el contexto escolar y que son reflejo de la realidad social cotidiana; cuestión que no siempre es percibida por los adultos, dado que no siempre en el espacio laboral se logran dar los espacios para interactuar y profundizar en aspectos culturales del país de destino que les permitan situar algunas cuestiones valóricas o morales. Esto último también resulta válido en el caso de madres o padres que desempeñan trabajo doméstico, quienes ven limitada aún más su posibilidad de interacción con el medio y sus códigos.

Lo anterior,se relaciona directamente con la subcategoría estilos educativos familiares. Podemos identificar en los discursos de los y las adolescentes dos tipos de socialización: la primera de estilo estricta y la segunda participativa. Ante esto, vemos que existe una mayor tensión con aquellas prácticas asociadas a un estilo estricto, puesto que esta subcategoría - en algunos casos- se encuentra asociada a prácticas parentales autoritarias, que incluyen dentro de su repertorio diferentes tipos de violencia vinculadas al maltrato verbal o la comunicación de tipo violenta; sin duda, ello se constituye en una situación de vulneración de derechos, de acuerdo a los instrumentos y normativa internacional vigente de derechos humanos, así como frente a la Convención por los Derechos del Niño.

La tensión cultural producida en este sentido es algo revestido de gravedad en términos de las consecuencias que este tipo de acciones coercitivas y violentas generan en el país de destino; a lo que se suma el grado de desconocimiento por parte de dichos adultos sobre el funcionamiento del sistema de protección de niñas, niños y adolescentes en Chile. Por otra parte, esta situación provoca una tensión cultural en el sentido que, en los diversos contextos donde se visualizan este tipo de situaciones, se puede asentar la idea de vincular la acción parental específica de ciertos cuidadores a su nacionalidad, esto es, estigmatizar a un grupo social por acciones particulares. A continuación, se presenta un relato que ejemplifica lo señalado:

Igual mi madre está cambiando un poco porque acá en Chile si pegas a niños te van a meter en cárcel y nosotros hablamos muy fuerte y a veces mi mamá está hablando muy fuerte 
como grita y los vecinos creen que estamos peleando y van a llamar a carabineros y todo eso; y dijimos que nosotros hablamos muy fuerte, pero en Chile hablamos bajo y cuando hablamos fuerte piensan que estamos peleando. (Sujeto 7, femenino, 15 años, Haití)

Ante esto, es necesario ser enfáticos en que la exposición de esta tensión cultural no reviste justificación para situaciones de maltrato y que impliquen vulneración derechos para niñas, niños y adolescentes. Claramente, la diversidad y perspectiva intercultural en lo relativo a crianza, normas y parentalidades, sienta sus bases y deslinda sus límites en los consensos internacionales en materia de derechos humanos.

Por último, frente a las tensiones culturales expuestas a nivel individual y familiar, emerge como subcategoría los mecanismos de resolución empleados como estrategias de respuesta frente a las diversas tensiones culturales que deben afrontar los y las adolescentes, tanto a nivel individual como familiar en sus trayectorias migratorias. En primer lugar, tenemos la integración, entendida como actitudes que propenden a la adaptación de los y las adolescentes migrantes, bajo el supuesto de una asimilación de algunos aspectos de la cultura dominante; tal como se muestra a continuación:

Algo que he tratado de hacer últimamente como para tratar de comunicarme muchísimo mejor cuando salgamos a la nueva normalidad es como tener un acento neutro; usar palabras neutras que sean tipo set de televisión, que todo el mundo, en todos los países, las puedan entender; entonces así aprendiendo a hablar para que así se entienda mucho mejor. (Sujeto 6, masculino, 16 años, Venezuela)

Como se observa, los y las adolescentes, con el objetivo de ser integrados, moderan aspectos de su comportamiento que a su parecer pudieran generar mayor tensión cultural o distancias para la interacción con pares principalmente; ello supone la adaptación de la subalteridad frente a la cultura dominante.

En segundo lugar, la subcategoría resistencia, como un mecanismo que reconoce la tensión cultural existente y se inclina hacia la preservación de los elementos culturales de origen. En términos generales, esta resistencia se expresa en cuanto a no incorporar modismos o costumbres de Chile, con el objetivo de no perder la riqueza cultural de su país natal. Esta idea, a menudo reforzada por la familia y amistades transnacionales, hacen hincapié en las acciones que pudieran significar aculturación. Algunos relatos que visibilizan lo señalado son: 
A veces se me sale alguna palabra chilena y me dicen: ya, te chilenizaste; y yo como: no, perdón, se me olvidó. (Sujeto 2, femenina, 15 años, Venezuela)

En la forma de hablar cuando se me sale eh, bueno, cuando hablo como chilena, mi mamá siempre es como, ¿porqué hablas así si tú no naciste aquí? No hables así; y es tipo mamá, no sé, solo se me sale. (Sujeto 5, femenina, 14 años, Colombia)

Dicha resistencia intenta hacerse consciente por parte de los y las adolescentes, dado que sus familias no valoran chilenizarse. Ante esto, en general las familias despliegan estrategias de preservación cultural por medio de la realización de ritos y costumbres del país de origen: celebración de festividades, preparaciones gastronómicas, desarrollo cultural y musical, reproducción de elementos lingüísticos e idiomáticos, entre otros.

Por último, la subcategoría exclusión alude principalmente a mecanismos que apuntan a la separación y distanciamiento de los y las adolescentes frente a sus pares del país de destino. Ante esto, destaca el aislamiento como forma de evadir la interacción y la relación exclusiva con adolescentes migrantes, tendiendo a la segregación en el espacio escolar. A continuación, un relato que respalda lo señalado:

Hubo un tiempo en donde a la hora de almuerzo me sentaba yo sola y ellos me decían: Ay no [nombre de la adolescente] vente, siéntate con nosotros. Pero era como que no me sentía cómoda. (Sujeto 2, femenina, 15 años, Venezuela)

De acuerdo a lo señalado, es necesario considerar que los diversos posicionamientos de los inmigrantes confluyen con elementos individuales y contextuales, los cuales, a su vez, no son estáticos. Dichas tensiones pueden resolverse con el pasar del tiempo o el abordaje de algunos de los puntos más críticos de conflicto o tensión cultural (Berry, 1997, como es citado en Martín, 2017). Por otra parte, es necesario visibilizar que cada uno de estos mecanismos de resolución presentes en los discursos, desde una perspectiva intercultural crítica (Dietz, 2020), refuerza la presencia de una desigualdad estructural, basada en lógicas etnocentristas y de dominación cultural puesto que, en este caso, los y las migrantes no son valorados debido al desbalance de poder que concentran y son vistos como grupo social que debe asimilar y adecuarse en función de la cultura de destino. En otras palabras, estos tres mecanismos de resolución constituyen por sí mismos una situación de violencia y exclusión, como grupo subalterno sin mecanismos legítimos para poder convivir en concordancia a sus valores, costumbres y cultura. 


\section{Discusión}

A la luz de los resultados se evidencia cuáles son las tensiones culturales vivenciadas por adolescentes migrantes en Chile. En primer lugar, dentro del plano individual, el manejo idiomático es una de sus principales dificultades (principalmente para quienes provienen de Haití); la barrera idiomática se transforma en un obstaculizador para la interacción tanto con sus pares como en diversos contextos sociales, gatillando situaciones de bullying encubierto o manifiesto. Ante estas tensiones culturales, es importante visibilizar el rol y desafío de las parentalidades migrantes, frente a la doble condición de activar procesos de transmisión cultural y perpetuación de la lengua materna, junto a la generación de estrategias inclusivas en el país de destino, puesto que en el seno familiar y en el espacio íntimo se comparte a nivel lingüístico un código diferente del que los y las adolescentes desarrollan en el espacio público.

Es evidente que en las trayectorias migratorias se generen diversos procesos de negociación de elementos culturales; frente a esto, la resistencia a la aculturación por parte de quienes ejercen el rol parental es significativa, puesto que su actuación incide en la actitud y percepción de los y las adolescentes frente a la apertura cultural en el país de destino. Esto, sumado a la ausencia de una política pública inclusiva en el contexto escolar que pueda desplegar estrategias de mediación (en donde, desde una perspectiva intercultural se logre valorar la diversidad desde la co-construcción de un habitus de significados compartido), termina por reproducir los mecanismos de violencia a través de los cuales se perpetúa la exclusión de la condición de sujeto migrante y que se cristalizan en los procesos de construcción identitarios.

Por otra parte, es importante señalar el tipo de interacción con pares, asociada al bullying como una tensión importante y de la mayor preocupación, ya que comparte el componente cultural vinculado a estereotipos reproducidos en el espacio escolar, como también la invisibilización generalizada de la incidencia de los pares transnacionales en la construcción de la identidad social, tanto respecto de cómo son vistos y reconocidos por el entorno, como también el autoconcepto de adolescentes migrantes. Esta situación es susceptible de generar una doble tensión cultural, desde la cual los y las adolescentes interpretan la inclusión como la negación de su propia cultura de origen.

En el plano familiar, podemos ver la tensión producida respecto de la apertura cultural, generando tensión en los espacios sociales de interacción; ello dado que el choque 
cultural se evidencia en cuestiones cotidianas tales como: el uso del vestuario, el uso del tiempo libre, las prácticas educativas formales e informales, el establecimiento de relaciones de pareja, la visión que se tiene de distintos grupos con prácticas alejadas de los valores o costumbres del país de origen, así como también en la evaluación del tipo y características de la sociedad receptora. Lo anterior es un elemento mediado en gran parte por la coparticipación de cuidados y transmisión cultural que se da al interior de la familia transnacional, en donde quienes permanecen en el país de origen actúan como grupo control contra la aculturación; ello también media en el cómo se desarrolla la parentalidad, no tan solo a partir de los patrones culturales internalizados, sino también a través los niveles de adaptación de algunas conductas de modo que sea consecuente con los elementos de origen y destino.

Frente a las diferentes tensiones culturales descritas, los y las adolescentes han desarrollado mecanismos de resolución, los cuales en su mayoría son excluyentes o propician la negación de elementos culturales de destino para hacer más llevadera la experiencia. Esto no facilita la interacción, sino que aumenta la atomización social y, con ello, la potenciación de factores de riesgo asociados a los procesos de desadaptación social. Por su parte, la integración, aun cuando supone la adecuación o sincretismo de aspectos culturales de origen, no resulta ser inclusiva debido a que opera desde la homogenización, resultando una de las estrategias más recurridas en términos de lograr adaptarse a la nueva sociedad de destino. En efecto, se advierte la inexistencia de mecanismos de resolución de las tensiones culturales descritas por mecanismos de inclusión. Desde el punto de vista relacional, podemos señalar que estos mecanismos han sido construidos a partir de la experiencia individual, pero también desde los contextos familiares y sociales en los que se desenvuelven.

En este sentido, resulta urgente desarrollar acciones desde el espacio familiar y escolar que apunten al desarrollo de trayectorias inclusivas desde un enfoque intercultural, ya que la rigidez cultural y escasa apertura o rechazo entre culturas finalmente propicia el mantenimiento de situaciones de discriminación, xenofobia y racismo. Esto no desconoce los aspectos coyunturales que reproducen la violencia a nivel social y cultural, tales como el etnocentrismo y nacionalismo, como estructuras de dominación a grupos históricamente marginados, a partir de los desequilibrios de poder y desprecio a la diversidad cultural.

Finalmente, a la luz de los resultados y relevando la dimensión transnacional tanto de la familia como de las redes focales (como es el caso de los pares del país de origen 
para los y las adolescentes), consideramos relevante profundizar en investigaciones que den cuenta de la interconexión existente en el plano material e inmaterial de la cultura, en tanto resulta de interés preguntarnos por el cómo los flujos de intercambio bidireccionales en la familia transnacional y redes focales incidirían en el desarrollo de trayectorias migratorias inclusivas de adolescentes migrantes.

\section{Agradecimientos}

Se agradece el apoyo brindado por el proyecto Converging Horizons: Production, Mediation, Reception and Effects of Cultural Representations of Marginality (SOC180045), Agencia de Investigación y Desarrollo de Chile.

\section{Referencias}

Aparicio, R., \& Tornos, A. (2009). Migraciones: diversidad cultural y teoría de la cultura.

Papers: Revista de Sociología, 94, 139-153. https://doi.org/10.5565/rev/papers/v94no.692 Arriagada, V. (2019). Repensar el rol de los niños, las niñas y los adolescentes en los movimientos transnacionales desde el enfoque centrado en los niños: apuntes para la familia transnacional. Revista Academia y Crítica, (3), 106-122.

Bravo, C., Vergara, J., \& Ordóñez, A. (2021). El Pawkar Raymi como afirmación de la identidad étnica en la migración: el caso de los migrantes kichwa-otavalo en Santiago de Chile. Estudios Atacameños, 67, 1-21. https://doi.org/g8wc

Dietz, G. (2020). Interculturalidad: una aproximación antropológica. En S. Brito-Rodríguez, L. Basualto-Porra, \& R. Urrutia-Arroyo (Eds.) Interculturalidad(es) y migraciones: desafíos desde una ciudadanía emergente (pp. 17-45). Aún Creemos en los Sueños.

Duarte, C. (2015). El adultocentrismo como paradigma y sistema de dominio: análisis de la reproducción de imaginarios en la investigación social chilena sobre lo juvenil. [Tesis de doctorado]. Universitat Autònoma de Barcelona.

Fernández-Hawrylak, M., \& Heras, D. (2019). Familias transnacionales, familias inmigrantes: reflexiones sobre su inclusión en la escuela. RASE, Revista de Sociología de la Educación, 12(1), 24-39. https://doi.org/10.7203/RASE.12.1.12787

Gonzálvez, H. (2016). Las familias transnacionales, ¿una tautología? Más allá de la dicotomía distancia/proximidad geográfica. Polis. Revista Latinoamericana, 15(43), 511-532. https://doi.org/10.4067/So718-65682016000100024 
Henao-Agudelo, C., Lalueza, J. L., \& Tenorio, M. C. (2016). Valores y prácticas educativas de familias latinoamericanas inmigradas en Barcelona: ¿qué cambia y qué permanece? Revista Latinoamericana de Ciencias Sociales, Niñez y Juventud, 14(1), 603-615.

Ibáñez, K. (2020). Construcciones identitarias migrantes: identidades en resistencia e identidades estratégicas en niños y niñas haitianos en Santiago de Chile. Revista Innova Educación, 2(2), 260-279. https://doi.org/10.35622/j.rie.2020.02.003

Lemus, E. (2020). Una perspectiva transnacional, migratoria e intercultural sobre las familias. Revista Inclusiones, 7(número especial), 65-73.

Martín, R. (2017). Estudios de aculturación en España en la última década. Papeles del Psicólogo, 38(2), 125-134. https://doi.org/10.23923/pap.psicol2017.2826

Masferrer, C. (2016). Yo no me siento contigo: educación y racismo en pueblos afromexicanos. Diálogos Sobre Educación, 13(7), 1-16. https://doi.org/10.32870/dse.voi13.227

Pareja, B. (2019). Aculturación, salud mental y adaptación psicosocial de los adolescentes inmigrantes en España [Tesis de pregrado, Universidad Pontificia Comillas]. Repositorio Comillas. http://hdl.handle.net/11531/31801

Pavez-Soto, I., Galaz, C., Poblete-Godoy, D., Acuña, V., \& Sepúlveda, N. (2020). Horizontes de la intervención social con infancia migrante en Chile. Revista Rumbos TS, (23), 9-40. https://doi.org/10.51188/rrts.num23.403

Pavez-Soto, I., Ortiz-López, J., Jara, P., Olguín, C., \& Domaica, A. (2018). Infancia haitiana migrante en Chile: barreras y oportunidades en el proceso de escolarización. Entre Diversidades, (11), 71-97. https://doi.org/10.31644/ED.11.2018.a03

Pavez-Soto, I., Ortiz-López, J., Sepúlveda, N., Jara, P., \& Olguín, C. (2019). Racialización de la niñez migrante haitiana en escuelas de Chile. Interciencia, 44(7), 414-420.

Poblete, R., \& Galaz, C. (2017). Aperturas y cierres para la inclusión educativa de niños/as migrantes en Chile. Superintendencia de Educación.

Ramírez, J. (2020). El vínculo afectivo en la distancia: la familia transnacional. TSnova. Trabajo Social y Servicios Sociales, (16), 65-74.

Ramírez, M. C. (2021). Aculturación y bienestar psicológico en estudiantes universitarios migrantes de una universidad privada de Trujillo [Tesis de pregrado]. Universidad Privada del Norte.

Riquelme, S., \& del Valle, C., Zambrano, A., Vera, N., \& Lucumi, A. (2019). Manual de redes de apoyo para migrantes en La Araucanía: avances para la inclusión. Ediciones Universidad de La Frontera. 
Romero, S., Moreno-Morilla, C., \& García, E. (2021). La construcción de las identidades culturales en niñas y niños migrantes: un enfoque desde la etnografía colaborativa. Revista de Investigación Educativa, 39(2), 483-501. https://oi.org/10.6018/rie.441411 Sánchez-Castelló, M., Navas, M., Ordóñez-Carrasco, J., \& Rojas A. (2020). Aculturación $\mathrm{y}$ adaptación de adolescentes de origen inmigrante en España: perfiles psicosociales de clases latentes. Revista Internacional de Psicología Social, 35(3), 560-588. https:// doi.org/10.1080/02134748.2020.1783836

Sánchez, M., Fernández, M., \& Díaz, J. (2021). Técnicas e instrumentos de recolección de información: análisis y procesamiento realizado por el investigador cualitativo. Revista Científica Uisrael, 8(1), 107-121. https://doi.org/10.35290/rcui.v8n1.2021.400

Strauss, A., \& Corbin, J. (2002). Bases de la investigación cualitativa: técnicas y procedimientos para desarrollar la teoría fundamentada. Editorial Universidad de Antioquia.

Tijoux, M. E., \& Palominos, S. (2015). Aproximaciones teóricas para el estudio de procesos de racialización y sexualización en los fenómenos migratorios de Chile. Polis. Revista Latinoamericana, $42(1), 42-67$.

Velandia-Coustol, C. R., Navas-Luque, M., \& Rojas-Tejada, A. J. (2018). El modelo ampliado de aculturación relativa (MAAR): balance y perspectivas de investigación. Revue Europeenne des Migrations Internationales, 34(2-3), 1-19. https://doi.org/g8wg

Wheeler, L. A., Arora, P. G., \& Delgado, M. Y. (2020). The distal role of adolescents' awareness of and perceived discrimination on young adults' socioeconomic attainment among Mexican-origin immigrant families. Journal of Youth Adolescence, 49, 2441-2458. https://doi.org/10.1007/s10964-020-01276-0

Zúñiga, V. A. (2017). Los niños y las niñas migrantes en escena. Sinéctica, (48), 627-643. 